\title{
Digital Images and Globalized Conflict
}

Blaagaard, Bolette; Mortensen, Mette; Neumayer, Christina

Published in:

Media, Culture \& Society

DOI:

$10.1177 / 0163443717725573$

Publication date:

2017

Document version

Peer reviewed version

Citation for published version (APA):

Blaagaard, B., Mortensen, M., \& Neumayer, C. (2017). Digital Images and Globalized Conflict. Media, Culture \& Society, 39(8), 1111-1121. https://doi.org/10.1177/0163443717725573 
Introduction to Special Section of Media, Culture \& Society (2017) vol. 39, no. 8: Digital Images and Globalized Conflict.

Please reference the published version of the article:

Blaagaard, Bolette, Mortensen, Mette \& Neumayer, Christina (2017) "Digital Images and Globalized Conflict" Media, Culture \& Society. 39(8): 1111-1121. 


\title{
Digital images and globalized conflict
}

\section{Bolette Blaagaard}

Aalborg University, Denmark

\section{Mette Mortensen}

University of Copenhagen, Denmark

\section{Christina Neumayer}

IT University of Copenhagen, Denmark

\begin{abstract}
As the number of digital images of globalized conflicts online grow, critical examination of their impact and consequence is timely. This editorial provides an overview of digital images and globalized conflict as a field of study by discussing regimes of visibility and invisibility, proximity and distance, and the multiplicity of images. It engages critically with these interlinking themes as they are addressed in the contributing articles to the Special Issue as well as beyond, asking how genres and tropes are reproduced, how power plays a role in access to images, and how the sheer quantity of conflict-related images raise issues of knowledge production and research.
\end{abstract}

\section{Keywords}

digital images, globalized conflict, multiplicity of images, operative images, proximity and distance, usergenerated images, visibility

Digital media, particularly mobile media, have fundamentally and dramatically altered the role that images play in conflicts by easing access to creating and sharing photographs and videos. Digital images do more than just change the way in which conflicts are represented; conflicts themselves change as the decline in control over image flow contributes to shaping, escalating, de-escalating, and even creating conflicts (e.g. Allan, 2013; Andén-Papadopoulos and Pantti, 2011; Eder and Klonk, 2017; Mortensen, 2015a; Zelizer, 2010). Over the past decades, the rapid and extensive dissemination of images from conflicts has intensified the struggle for public visibility. This has encouraged competing visual narratives and counter narratives, persistent allegations of falsification and manipulation, yet also resulted in unprecedented access to more 'unfiltered' and subjective images from conflicts, documenting violence, human rights violations, and mundane aspects of daily life in conflict zones.

As the title of this Special Issue 'Digital Images and Globalized Conflict' suggests, the role of images in conflicts today is conditioned by their increasingly globalized circulation through digital media. Existing scholarship has persuasively argued that conflicts are now connected across the globe through the dissemination of images via networked technologies (perhaps most prominently; Castells, 2012). Even if images cross regional, cultural, and linguistic borders, however, they are received and interpreted in often divergent and conflicting manners in different social, cultural, and geopolitical contexts, prompting diverse readings, meanings, and actions. 
Concurrent with the globalized flow of images, mobile media have enabled citizens and participants in conflict to produce and disseminate images to document their experiences, mobilize and recruit, sway public opinion, contest the legitimacy of authorities, secure legal evidence, and appeal for humanitarian relief (e.g. Ling, 2012; Neumayer and Stald, 2014). This development influences the number and types of visuals available, as aspects of conflicts formerly held confidential by military and state are now potentially publicly available. While news media and professional journalists still play an important role in selecting images of conflict for publication, they increasingly compete and converge with those involved in bottom-up dissemination, for instance, by building up their social media presence and using citizen images in their own reporting (e.g. Allan, 2013; Andén-Papadopoulos and Pantti, 2011; Mortensen, 2015a). Moreover, users of social media and other online outlets contribute to circulating and mobilizing images, especially in relation to urgent crisis situations, such as terrorist attacks and humanitarian suffering.

Concomitantly, the influence of digitalization on images and conflicts cannot be reduced to the multiplicity and diversity of perspectives or to simple causalities between the 'message' of an image and its impact. Digitalization has profound effects on the politics of visibility due to changing qualitative and quantitative characteristics of images. When it comes to qualitative changes, digital images reconfigure the axis of distance and proximity, frequently understood as fundamental to ethical response and action (Chouliaraki, 2006; Silverstone, 2007). This is discernible in new genres such as visuals created and disseminated by citizens and participants, which may not only allow different perspectives and positions to vie for empathy and action but also tend to present conflicts in a decontextualized and fragmented manner. Regarding quantitative changes, digital media have led to an unprecedented increase in image production. While this development has prompted hope for digital democracy and equality (Dahlgren, 2013; Howard, 2010), hierarchies upheld by commercialization, commodification, and algorithmic structuring persist.

At this decisive moment for the role performed by images of and in conflict, traditional approaches to studying conflict and images in terms of propaganda, censorship, and news frames can no longer stand on their own. New empirical insights, theoretical frameworks, and analytical concepts need to be developed. The five articles compiled in this Special Issue combine to do exactly this. The authors advance original perspectives on the study of digital images and globalized conflict by taking a fresh look at the specific digital modalities of dissemination and mobilization, the actors involved, and emerging visual typologies and genres. In the first article, Axel Bruns and Folker Hanusch investigate how Twitter users distributed various genres of images in the wake of the terrorist attacks in Paris (2015) and Brussels (2016). They reconceptualize 'the witness' to think anew the role that individual actors - both human and non-human - play in disseminating visual content in relation to unfolding crisis events. The second article, by Mette Mortensen, also focuses on dissemination of images through Twitter. Taking her point of departure in the prominent imagery of the drowned refugee boy, Alan Kurdi, Mortensen draws upon theories of icons to show how appropriations construct, confirm, and contest icons through personification. In their article, Lilie Chouliaraki and Tijana Stolic address visual representations of the so-called 'refugee crisis' (2015) and propose a typology of motifs and themes based on news photographs published in European newspapers. In the fourth article, Lina Dencik and Stuart Allan analyze the interplay between non-governmental organizations (NGOs) and journalists in determining how conflicts are represented to heighten the public's level of information and mobilize support. The fifth article, by Marwan Kraidy, analyzes an Islamic State of Iraq and Syria (ISIS) propaganda video and identifies a key modality of a new kind of warfare that uses images as its 'weapon' in what he terms 'global networked affect'. 
In the remainder of this introduction, we wish to outline digital images and globalized conflict as a field of study by critically addressing interlinking themes that emerge across the contributions to this Special Issue: First, we engage with the overall debate concerning how digital images reconfigure the visibility (and invisibility) of conflicts, as more actors are involved in documenting conflicts and in circulating and mobilizing images. Second, we discuss how images may qualitatively act and perform - rather than merely represent - conflict. Third, we reflect upon the ambiguity of the knowledge production that arises from the sheer quantity of conflict-related images and its implications for research, before concluding on the contribution made by this Special Issue to the study of digital images and globalized conflict.

\section{The politics of visibility}

Digital images are key to rendering conflicts visible or invisible. Some conflicts are thoroughly exposed in Western media, such as the Syrian conflict and the subsequent 'refugee crisis' in Europe and the Middle East. Four contributions to this Special Issue reference the globalization of the conflict in Syria in one way or another. Focus rests on two particular aspects of this conflict: the imagery of ISIS, i.e. its attacks in Syria and Europe and its own visual representation of its actions and goals (Bruns and Hanusch; Kraidy) and representations of victims and refugees of the Syrian conflict (Mortensen; Chouliaraki and Stolic). Other conflicts remain largely invisible and underrepresented in Western media, such as the conflict in Yemen. Dencik and Allan investigate the invisibility of these conflicts and NGOs' pleas for international attention. Despite the intensity and volume of digital images, some crises remain overlooked. Social media attention spans are fleeting and more or less coincidental (Bennett and Segerberg, 2013; Papacharissi, 2015), neglecting some images and allowing others to rise to the top of trending boards as instant icons, as Mortensen observes in her article. 'Regimes of visibility', as Chouliaraki and Stolic put it, dictate the representation of others to a Western 'us' and endow these representations with value and legitimacy. That is, these images draw upon certain recognizable genres and tropes, while other images may be rendered invisible due to their lack of recognizability in the eye of the Western viewer. The regimes of visibility encourage NGOs to cooperate with photojournalists, as Dencik and Allan maintain. Humanitarian organizations attempt the difficult balance of communicating the specific needs of their causes while protecting the dignity of those who have suffered from conflict.

As Nicholas Mirzoeff (2011) pointedly argues, structures of visibility and invisibility are used to classify and separate individuals. This brings about an aesthetic order among people and generates a 'complex of visuality' (Mirzoeff, 2011: 34). Leaning on a definition of Foucault's (1977) Benthamian panopticon as a disciplinary mechanism based on the 'eyes that must see without being seen' (p. 171), both visuality and surveillance are disciplinary powers that normalize judgement and function as 'value-giving' measures. As a result, 'the perpetual penalty [of] the disciplinary institutions compares, differentiates, hierarchizes, homogenizes, excludes. In short, it normalizes' (Foucault, 1977: 183, italics in original). The selection of which wars and conflicts are visible - and thus deemed important - and which are not might be thought of as a process of normalization, desensitizing us and closing our eyes to the hierarchies and exclusions it sustains. However, visuality - if not surveillance - may be countered by the right to look. Mirzoeff argues that in order for visuals and visibility to serve democratic ends, it is necessary for accessibility to extend to more than just image production and circulation. Marginalized individuals and groups must instead be able to claim the right to be seen on their own terms and using their own aesthetics. As Daniel Dayan (2013) contends, 'the visibility-deprived are not merely intent on acquiring visibility [...] they mean to acquire it on their own terms' (p. 141). 
While citizen-driven media may in turn serve to disrupt the political and cultural logics of Western audiences (Baker and Blaagaard, 2016), this raises the question of whether the options that digital media make available for actors involved in conflict to represent their experiences and perspectives genuinely challenge implicit and explicit hierarchies of visibility. The struggle for mediated visibility has intensified in today's commercial and competitive media landscape of increased fragmentation and seemingly easier access to mediated visibility (see also Hjarvard, 2013; Thompson, 2005). Dayan (2013) highlights how citizens may assume the role of 'visibility entrepreneurs' who are 'performing a function that journalists see as a task but that many others perceive as a privilege', namely, 'conferring visibility' ( $\mathrm{p}$. 143). However, conferring visibility does not necessarily amount to obtaining visibility as ever-more actors enter the contested field of mediated visibility. New 'visibility entrepreneurs' appearing on the scene may to some degree reconfigure the traditional distribution of power inherent in the politics of visibility (i.e. who possesses the cultural and social status as well as the geopolitical situatedness to be seen and heard). Be that as it may, established hierarchies hardly seem to be subverted at this point. Indeed, commercialization and commodification potentially threatens to hand alternative visual expressions over to the corporate power of media institutions (Baker and Blaagaard, 2016: 16).

This leaves us with the question of whether and to what extent bottom-up processes of image production and dissemination alter the salient representations of conflict. While more empirical analyzes are required, the contributions to this Special Issue do not suggest that digital images and globalized conflicts bring about greater diversity in the representations of gender, race, age, and so on, in the context of conflict. At one end of the spectrum, the articles by Chouliaraki and Stolic and Mortensen point to representations of refugees being confined to more-or-less schematic visualizations of women and children as 'ideal victims', while Kraidy's article at the other end of the spectrum concerns the projection of hyper-masculine 'warrior' identities by terrorists. The continued (re) production of images that fall neatly into stereotypes of female victims and masculine perpetrators risks essentializing victims of war and conflict as emotionally charged and geopolitically dependent on Western help and pity. Moreover, these images play a significant role in our own everyday understandings of conflict and of sufferers' perceived lack of agency and autonomy (Zarzycka, 2012).

Regimes of visibility thus still pose a fundamental challenge to scholarly work on images in general and perhaps to media studies in particular. Contention remains regarding who is the spectator and who is the object, and the power relations that this entails. Globalized, digital images are disseminated and circulated in accordance with geopolitical borders, recognizability, and politics of representation and visuality. This in turn raises methodological and theoretical questions about how we conceptualize and measure visibility as well as how we reflect upon our own positioning as researchers.

\section{Genres of distance and proximity}

Moving from the politics of visibility to prevalent types and genres, a range of images produced by various actors has entered the public representation of conflict. Citizens, eyewitnesses, and actors actively involved in conflicts as well as surveillance technologies, such as gun camera images and drone images, have altered proximity to and distance from the visuality of conflicts. The photographs of prisoners being tortured in Abu Ghraib prison in Iraq, taken by American guards and made public in 2004, augured this development (e.g. Eisenman, 2007; Sontag, 2004). These photographs point to a blurring of conventional boundaries between taking active part in and documenting conflict, which is arguably among the most conspicuous changes brought about by digital images and globalized conflict. The Abu Ghraib images might have drawn audiences closer to war and provided an uncensored and less filtered glimpse into the grim realities of human rights violations, but they simultaneously raised 
ethical questions concerning the role of the spectator and how to maintain 'proper distance' (Silverstone, 2007) when perpetrators are behind the camera (Mortensen, 2015a; Struk, 2011).

Experiences of proximity and distance entailed by the materiality of photography have been an enduring scholarly concern. Writing in 1927, Siegfried Kracauer ([1927] 1993) notes loss of proximity due to the material character of photography: 'Photography shows cities in aerial shots, brings crockets and figures down from the Gothic cathedrals; [...] in unusual combinations that distance them from human proximity' (p. 435). Today, the materiality of digital images underscores their physical remoteness from conflicts, yet images transmitted through screens can also create intimacy and even an experience of proximity by collapsing spatial and temporal distance. Two formats have gained particular prominence in the last few years, reconfiguring the spatial and temporal experience of conflict obtained through images by performing the dual role of documenting and being embedded in conflicts: 'operative images' and images taken by participants in conflicts. We are going to elaborate on the two formats in the following.

'Operative images', to borrow a term from Farocki (2004, see also Kraidy, this issue), for example, in the form of aerial surveillance, have been instrumental in warfare at least since the World Wars. They gained public attention in the 1990s as a routine feature of press briefings by the US military. Critical voices argued that this footage worked to sanitize conflict by offering an instrumental aerial perspective, creating remoteness from human suffering and death inflicted by air strikes (e.g. Aday, 2005). More recently, operative images have been leaked to the public through digital media on a number of occasions and have been used by actors seeking to provide evidence of war crimes. The most prominent example is perhaps WikiLeaks' publication of the gun video 'Collateral Murder' in 2010, which documented the shooting of two Reuters staff by the US military in Iraq (Christensen, 2014; Mortensen, 2014). Although these images provide us with a distant and instrumental perspective on war, they can also produce empathy for the unknown and invisible victims.

Images taken by participants in conflict have over the past decade granted insight into conflicts from insiders' subjective and personalized perspectives. At the same time, photographs and videos taken by terrorists, soldiers, activists, citizens, and so on, can be said to create distance due to their lack of accessibility to outsiders for whom they often come across as selective, fragmented, and difficult to decipher (e.g. Allan, 2013; Andén- Papadopoulos, 2014; Andén-Papadopoulos and Pantti, 2011; Mortensen, 2015a; Pantti, 2013). The repertoire of genres that can gain public visibility in today's digital media has expanded due to the introduction of these 'privately' shot images, which do not conform to the traditional realism of photojournalism. In this Special Issue, Dencik and Allan and Chouliaraki and Stolic take their empirical points of departure in news photography and photojournalism, while the remaining articles analyze genres such as propaganda material and user-generated drawings, cartoons, memes, and collages. These genres are typically within the realm of the mundane, with references to popular culture and within vernacular formats. Whereas photojournalistic images have often been accused of manipulation and bias, they nevertheless possess a certain claim to representing reality, which is not upheld in the more performative genres adopted in many bottom-up produced images.

Different genres and formats - for instance, drone images and participants' images - permit different aesthetic experiences of similar conflictual events (Blaagaard, 2015). Operative images and images taken by participants in conflict simultaneously facilitate extreme close-up and personal accounts of conflictrelated incidents and provide distance by dehumanizing conflict and obscuring the context in which it takes place. They are typically construed as authentic because they provide first-hand views from the perspectives of actors and practitioners experiencing the conflict, in contrast to the ethos and aesthetic conventions guiding professional photojournalism (Eder and Klonk, 2017). However, this often comes 
at the expense of understanding the wider facts and circumstances of the conflictual situation, thereby posing severe challenges to verification when this material serves as evidence or documentation.

Contextual knowledge about the source and the motif is often not preserved or accessible when these visuals drift in more- or-less predictable online patterns. As the images blur the boundaries between documenting and contributing to conflicts, comprehension of them often requires media savviness, if not specialist knowledge. They redraw distinctions between elites and non- elites, experts and laymen, in explicit and implicit ways (Mortensen, 2015b).

\section{Multiplicity of images}

The war in Syria is among the best-documented conflicts in history (Hankey and Tuszynski, 2017: 170). A multiplicity of images has been produced and circulated by various actors, especially since refugees fleeing the conflict began arriving in Europe in 2015. The articles in this Special Issue all discuss how the extensive supply of images becomes a concern as well as a resource for actors with strategic interests in shaping and influencing the digitally mediated visibility of conflicts. Images from conflict propagate, manipulate, confuse, mobilize, glorify, degrade, illustrate, document, and provide different truths for different contexts and different audiences. Since the infancy of the photographic medium, commentators have grappled with how to impose order upon the masses and multiplicities of images. 'Danger', observes Sekula (1986: 4), was believed to reside in the 'numerical proliferation of images', and archival logics soon surfaced to horizontally structure the ever-increasing number of photographs. As far as conflict reporting was concerned, the news media throughout the 20th century performed a gatekeeping role by selecting the photographs presented to the public. This meant, for instance, that snapshots taken by soldiers during the World Wars remained largely hidden from public viewing (e.g. Allan, 2011; Guerin, 2012; Heer and Naumann, 1995; Struk, 2011). The visual coverage of conflict was strongly conditioned by the press' interplay with military and state actors, which determined access to information from the frontlines (see, for example, Hallin, 1986; Hjarvard et al., 2015; Robinson, 2002).

Today, the sheer quantity of digitally mediated images produced and disseminated by a multiplicity of actors creates challenges and opportunities concerning the availability, construction, and 'meaning of knowledge' (Bruns, 2013, see also Hankey and Tuszynski, 2017). Hopes for democratization - in terms of opportunities for participating in public and online debates as well as of access to information were foundational to early discussions about digitalization (Gillmor, 2004). However, images do not simply float freely on digital media platforms, allowing equal access for all; much visual material remains invisible or appears to the public in an obscured fashion.

Algorithmic control becomes a primary mechanism for structuring and accumulating images from conflict, alongside the residual gatekeeping of professional journalists, broadcasters, editors, governments, and militaries. Images produced by participants in conflict areas can also be seen as products of unpaid labor, potentially being treated as commodities by corporations. First, images are handled as commodities in the form of data in line with all online participation, detailing users' personal preferences, habits, and statuses. These data are valuable to corporations seeking to develop strategies for future competitive markets and commercial ventures (see Fuchs and Sevignani, 2013; Sandoval, 2014). Second, user-produced images are commodified as products in their own right, at times causing corporations to challenge and circumvent copyright and intellectual property laws. This commodified visual data increase in value through dissemination, appropriation, redistribution, and reproduction. Images that receive public attention and visibility are algorithmically privileged over those that remain unnoticed, and as Thomas Poell and José van Dijck (2015) convincingly argue 'social media logic' favors images that are spectacular and depict violence (see also Bucher, 2012; Gillespie, 2010). 
Contributing to the politics of visibility, the materiality of social media platforms algorithmically structures that which is seen. Simultaneously, we can observe algorithmic censorship and surveillance of images in digital media. Techniques of obfuscation (Brunton and Nissenbaum, 2015) and new forms of disguised propaganda (Farkas et al., 2017) are tactically deployed to avoid mechanisms of control over images and other personal data, but such deployment also complicates issues regarding the authenticity and interpretation of digital images. Risk of surveillance is particularly high for individuals in conflicts who are on the side of the insurgent or anti-government faction, which can result in selfcensorship practices as part of struggles for visibility and recognition (Brighenti, 2007; Neumayer et al., 2016; Uldam, 2017).

Issues related to the multiplicity of images, public visibility, and authenticity lead to new methodological and epistemological challenges for media scholars. The images subjected to analysis in this Special Issue are publicly available through news media (Chouliaraki and Stolic) and public social media platforms such as Twitter (Mortensen; Bruns and Hanusch). Dencik and Allan address the problem of the invisibility of certain regions of conflict and suffering. This problem is not solely an ethical one but is also reflected in academic research, which is often based on images that are easy to access due to their social media availability (Neumayer and Rossi, 2016). Perhaps for understandable reasons, we tend to study images that are easily accessible and overrepresented in our immediate everyday (digital) media consumption. This tendency, however, raises the question of how we can develop more nuanced perspectives and processes of reflexivity when it comes to research on digital images and globalized conflict.

\section{Conclusion}

The contributions to this Special Issue shed light on the role images play in globalized conflicts and help us understand how digital images of conflicts can (re)shape public understanding of conflicts today. Moreover, the contributions introduce novel methods for understanding images as well as revisit traditional methods now challenged by new aspects of the empirical material. It is clear that digital images and the globalization of conflict do not present us with a simple recipe for understanding the changing field. Instead, they prompt us to open up the field and to encourage new approaches and perspectives.

Traditional actors, such as news media institutions and NGOs, are still powerful players when it comes to determining the visibility and importance of wars and conflicts. Chouliaraki and Stolic show how European news media represent refugees in five different modalities, each calling for a response from their Western viewer. Similarly, Dencik and Allan explore how negotiations between the ethics of photojournalism and of NGOs play out in efforts to attract viewers, donors, and political action. Dencik and Allan observe that NGOs do not make use of user-generated images, despite the multitude of such images available, adhering instead to long-held beliefs concerning journalistic ethics and credibility. However, social media users are highly productive and allow for new forms of witnessing and new ways of expressing or acting out empathy and indignation, as shown in the contributions by Bruns and Hanusch, and Mortensen. Kraidy analyzes how ISIS, as an actor newly arrived on the scene, shapes the digital sphere through affect and use of spectacle. While the actors differ, so do the platforms and networks connecting and directing the flows of digital images.

The ruptures of perspectives presented by new developments of digital media and global dissemination allow us to go beyond readings of normalizing conflict, as Foucault would have it. In her seminal work on the political ramifications of conflict images and frames of war, Judith Butler (2009) suggests that it is not only a question of finding new content, but also of working with received renditions of reality to 
show how [the frames] can and do break with themselves'(p. 12). Butler's radical suggestion brings to the fore the agency of frames and with them our received notions of reality, brought about through circulation and dissemination. Digitalization allows images to travel, and their unpredictable itineraries hold the potential to change meanings and thereby break through the assigned frames. That is, digital images - because of their material structures as assemblages - have agency and grant us an unprecedented possibility 'to apprehend something about what or who is living but has not been generally "recognized" as life' (Butler, 2009: 12). This notion of breaking frames of war could lead to 'alternative readings [...], which might establish new ruptures in our viewing of other people's lives, fundamental to the production and discussion of [...] photographs' (Zarzycka, 2012: 73). The globalized scope and digital make-up of many images of war today are arguably fundamental to bringing about such alternative or counter-readings.

Hierarchies of visibility and accessibility persist despite the abundance of images experienced today and the multiplicity of digital connections. If digitalization reconfigures regimes of visibility, it is not only because of increased access and distribution but also because of the circulation and dissemination of images, which challenge the frames and representations of conflicts around the world. Digital connectivities and social media platforms allow new representations to emerge from the bottom up. Digital images of conflict and their global circulation do more than just create new content; they create diverse interpretations and (re)productions of the same images, thereby altering their meanings and impact. Images perform and act in material ways.

\section{Funding}

The authors have received funding for the research of this article from the Velux Foundation through the research project Images of Conflict, Conflicting Images (2017-2021), University of Copenhagen, PI Mette Mortensen.

\section{References}

Aday S (2005) The real war will never get on television: casualty imagery in American television coverage of the Iraq war. In: Seib P (ed.) Media and Conflict in the Twenty-First Century. Gordonsville, VA: Palgrave Macmillan, pp. 141-156.

Allan S (2011) Amateur photography in wartime: early histories. In: Andén-Papadopoulos K and Pantti M (eds) Amateur Images and Global News. Bristol: Intellect Books, pp. 41-59.

Allan S (2013) Citizen Witnessing: Revisioning Journalism in Times of Crisis. Cambridge: Polity Press.

Andén-Papadopoulos K and Pantti M (2011) Amateur Images and Global News. Bristol: Intellect Books.

Andén-Papadopoulos K (2014) Citizen camera-witnessing: Embodied political dissent in the age of 'mediated mass self-communication'. New Media \& Society 16(5): 753-769.

Baker M and Blaagaard B (2016) Reconceptualizing citizen media: a preliminary charting of a complex domain. In: Baker M and Blaagaard B (eds) Citizen Media and Public Spaces. New York; London: Routledge, pp. 1-22.

Bennett WL and Segerberg A (2013) The Logic of Connective Action: Digital Media and the Personalization of Contentious Politics. Cambridge: Cambridge University Press. 
Blaagaard B (2015) The aesthetics of posthuman experience: the presence of journallistic, citizengenerated and drone imagery. Westminster Paper in Communication and Culture 10(1): 51-65.

Brighenti A (2007) Visibility: a category for the social sciences. Current Sociology 55(3): 323-342.

Bruns A (2013) Faster than the speed of print: reconciling 'big data' social media analysis and academic scholarship. First Monday 18(10). Available at: http://dx.doi.org/10.5210/ fm.v18i10.4879

Brunton F and Nissenbaum H (2015) Obfuscation: A User's Guide for Privacy and Protest. Cambridge, MA: MIT Press.

Bucher T (2012) Want to be on the top? Algorithmic power and the threat of invisibility on Facebook. New Media \& Society 14(7): 1164-1180.

Butler J (2009) Frames of War. London; New York: Verso Books.

Castells M (2012) Networks of Outrage and Hope: Social Movements in the Internet Age. Cambridge: Polity Press.

Chouliaraki L (2006) The Spectatorship of Suffering. London; Thousand Oaks, CA: Sage.

Christensen C (2014) WikiLeaks and the afterlife of collateral murder. International Journal of Communication 8: 2593-2602.

Dahlgren P (2013) The Political Web: Media, Participation and Alternative Democracy. Basingstoke: Palgrave Macmillan.

Dayan D (2013) Conquering visibility, conferring visibility: visibility seekers and media performance. International Journal of Communication 7: 137-153.

Eder J and Klonk C (2017) Image Operations: Visual Media and Political Conflict. Manchester: Manchester University Press.

Eisenman SF (2007) The Abu Ghraib Effect. London: Reaktion Books.

Farkas J, Schou J and Neumayer C (2017) Cloaked Facebook pages: exploring fake Islamist propaganda in social media. New Media \& Society. Epub ahead of print 19 May. DOI: 10.1177/1461444817707759.

Farocki H (2004) Phantom images. Public 29: 12-22.

Foucault M (1977) Discipline and Punish: The Birth of the Prison (trans. A Sheridan). London; New York: Penguin Books. 
Fuchs C and Sevignani S (2013) What is digital labour? What is digital work? What's their difference? And why do these questions matter for understanding social media? triple C11(2): 237-293.

Gillespie T (2010) The politics of 'platforms'. New Media \& Society 12(3): 347-364.

Gillmor D (2004) We the Media: Grassroots Journalism by the People, for the People. Sebastopol, CA: O'Reilly Media, Inc.

Guerin F (2012) Through Amateur Eyes: Film and Photography in Nazi Germany. Minneapolis, MN: University of Minnesota Press.

Hallin DC (1986) The 'Uncensored War': The Media and Vietnam. New York: Oxford University Press.

Hankey S and Tuszynski M (2017) Exposing the invisible: visual investigation and conflict. In: Eder J and Klonk C (eds) Image Operations: Visual Media and Political Conflict. Manchester: Manchester University Press, pp. 169-183.

Heer H and Naumann K (1995) Vernichtungskrieg: Verbrechen der Webrmacht 1941-1944. Hamburg: Hamburger Edition.

Hjarvard S (2013) The Mediatization of Society and Culture. New York: Routledge.

Hjarvard S, Mortensen M and Eskjær MF (2015) Introduction: three dynamics of mediatized conflicts. In: Eskjær MF, Hjarvard S and Mortensen M (eds) The Dynamics of Mediatized Conflicts. New York: Peter Lang, pp. 1-27.

Howard PN (2010) The Digital Origins of Dictatorship and Democracy: Information Technology and Political Islam. New York: Oxford University Press.

Kracauer S ([1927] 1993) Photography. Critical Inquiry 19(3): 421-436.

Kraidy MM (IN PRESS) The projectilic image: Islamic state's digital visual warfare and global networked affect. Media, Culture \&o Society.

Ling R (2012) Taken for Grantedness: The Embedding of Mobile Communication into Society. Cambridge, MA: MIT Press.

Mirzoeff N (2011) The Right to Look: A Counterbistory of Visuality. Durham, NC; London: Duke University Press.

Mortensen M (2014) Who is surveilling whom? Negotiations of surveillance and sousveillance in relation to WikiLeaks' release of the gun camera tape collateral murder. Photographies 7(1): 23-37. 
Mortensen M (2015a) Journalism and Eyewitness Images: Digital Media, Participation, and Conflict. New York: Routledge.

Mortensen M (2015b) Conflictual media events, eyewitness images, and the Boston marathon bombing (2013). Journalism Practice 9(4): 536-551.

Neumayer C and Rossi L (2016) 15 years of protest and media technologies scholarship: a sociotechnical timeline. Social Media + Society 2(3): 1-13.

Neumayer C and Stald G (2014) The mobile phone in street protest: texting, tweeting, tracking, and tracing. Mobile Media \& Communication 2(2): 117-133.

Neumayer C, Rossi L and Karlsson B (2016) Contested hashtags: blockupy Frankfurt in social media. International Journal of Communication 10(22): 5558-5579.

Pantti M (2013) Getting closer? Encounters of the national media with global images. Journalism Studies 14(2): 201-218.

Papacharissi Z (2015) Affective Publics: Sentiment, Technology, and Politics. New York: Oxford University Press.

Poell T and van Dijck J (2015) Social media and activist communication. In: Atton C (ed.) The Routledge Companion to Alternative and Community Media. London: Routledge, pp. 527-237.

Robinson P (2002) The CNN Effect: The Myth of News, Foreign Policy, and Intervention. London; New York: Routledge.

Sandoval M (2014) From Corporate to Social Media: Critical Perspectives on Corporate Social Responsibility in Media and Communication Industries. London: Routledge.

Sekula A (1986) The body and the archive. October 39: 3-64.

Silverstone R (2007) Media and Morality: On the Rise of the Mediapolis. Cambridge: Polity Press.

Sontag S (2004) Regarding the torture of others. The New York Times Magazine, 23 May. Available at: http://www.nytimes.com/2004/05/23/magazine/regarding-the-torture-of-others.html

Struk J (2011) Private Pictures: Soldiers' Inside View of War. London; New York: I.B. Tauris.

Thompson JB (2005) The new visibility. Theory, Culture \& Society 22(6): 31-51. 
Uldam J (2017) Social media visibility: challenges to activism. Media, Culture \& Society. Epub ahead of print 21 April. DOI: 10.1177/0163443717704997.

Zarzycka M (2012) Madonnas of warfare, angels of poverty: cutting through press photography. Photographies 5(1): 71-85.

Zelizer B (2010) About to Die: How New Images Move the Public. Oxford: Oxford University Press. 